\title{
Thermodynamic properties of the dodecylbenzenesulfonic acid-acetone binary liquid mixture using a modified flory theory
}

Ali A. Jazie*

Department of Chemical Engineering, College of Engineering, University of Al-Qadisiyah,Al-Qadisiyah, Al-Diwaniyah, Iraq. Article Info: Submitted on March 16, 2018, Accepted on June 1, 2018.

\begin{abstract}
:
Prigogine-Flory-Patterson (P-F-P) theory was applied for the correlation the experimental data of excess molar volume for the binary liquid mixture of DBSA-Acetone at the temperature range of (293.15-303.15 K). The three contribution terms (pressure, interaction and free volume) in the P-F-P equation were compared with the total effect of P-F-P equation. A positive excess molar volume were obtained at all the range of mole fraction and at all the temperatures. The maximum value of excess molar volume was positioned at the 0.4 mole fraction. Eyring-FloryHuggins theory was found useful in the estimation of the viscosity deviation variation with mole fraction at the same temperature range. A negative deviation was found in the viscosity for all the range of temperature and mole fraction. The maximum deviation in the viscosity was found at the mole fraction of 0.4. The increase in the negative deviation values with temperature was interpreted as a result of the decrease in the attractive forces between the like molecules.
\end{abstract}

Keywords: Prigogine-Flory-Patterson theory; Eyring-Flory-Huggins theory; Dodecylbenzenesulfonic acid; Acetone; Density; Viscosity; Excess molar volume; viscosity deviation.

\section{Introduction}

In the last decades, exploration the excess properties of binary liquid mixtures receives much more attention due to the complication of that mixtures and extensive use industrially. Many parameters effecting the excess properties of the liquid mixtures like polarity, no polarity and present of ions give the liquid mixtures more complexity than the solid and gas solutions. Presently, there are no theory explain the behavior of excess properties in the liquid solution. The most accepted theory was presented by Flory in the early of 1940s for the interpretation of the nonideal liquid solution behavior for the polymers and hydrocarbons 1,2. A modification for the Flory's theory was proposed as a new theory called Prigogine-Flory-Patterson (PF-P) theory ${ }^{3-9}$. The P-F-P theory modifies the dependence of excess thermodynamic properties into three terms: pressure term, interaction term and free volume term. Another modification for the Flory's theory had been proposed by Eyring for the viscosity deviation explanation and produced as Eyring-FloryHuggins theory 10,11 . Eyring related the dynamic viscosity to the activation energy in a new formula. Dodecylbenzenesulfonic acid is an important chemical substance used extensively in the industry as a surfactant and as an acid catalyst for a wide range of

*Corresponding Author: Ali A. Jazie

Email: Ali.Jazie@qu.edu.iq, Tel: 009647825221600 chemical reactions and polymer preparation 12-20 Acetone was used widely in the industry as a solvent alone or with other solvents. Many researchers investigated the activity of acetone as a solvent for many reactions. In a recent study, acetone and other types of ketones had been used as a solvent for hydrophobic and hydrophilic monomer reaction in the presence of a metal as catalyst ${ }^{21}$. Thermodynamic excess properties for a binary liquid mixture containing acetone was investigated in many studies 22-29 and showed the polar and self-associative behavior for the acetone molecules. The aim of the present study is to apply the Prigogine-FloryPatterson (P-F-P) theory and Eyring-Flory-Huggins theory for the excess molar property calculation and viscosity deviation. Moreover, aimed to provide an experimental data for the system of DBSA-Acetone regarding the density, viscosity, excess molar volume and viscosity deviation at three different temperatures (293.15 - 303.15 K).

\section{Experimental}

\section{Materials}

The Acetone of GC purity (>0.997) used in the experimental test were of analytical grade and obtained

CBangladeshUni.ofEngg.\&Tech30 


\section{Chemical Engineering Research Bulletin 20(2018) 30-35}

from Sigma-Aldrich, USA. Dodecylbenzenesulfonic acid (purity >0.99) was provided by Shanghai Hanhong Scientific Co., Ltd., and also of analytical grade.

\section{Measuring and procedure}

The preparation of the samples of different mole fraction in the range of 0.1-0.9 were done using OHAUS balance instrument. The precision of the electronic balance was of $\pm 10-4$. AntonPaardensometer was used for measuring the density of the pure substances and the binary mixture with a precision of $\pm 2 \times 10-3 \mathrm{~kg} \mathrm{~m}^{-3}$. A viscometer of the Anton-Paar model was used for the testing the dynamic viscosity of the samples with a precision of $\pm 0.06 \mathrm{mPa}$.s. The experiments were done in triplicate for each sample and the average of the three tests was taken in the calculation.

\section{Theoretical Basis}

\section{Prigogine-Flory-Patterson (P-F-P) theory}

The excess molar volume for the binary liquid mixture of DBSA-Acetone was estimated using the P-F-P theory. The theory assumes that the contribution of excess molar volumes can be attributed to the three terms of pressure, free volume and interaction contributions according the following equations (1-4):

$$
\begin{aligned}
& \frac{V^{E}}{X_{1} V_{1}^{*}+X_{2} V_{2}^{*}}=V_{\text {Pressure }}^{E}+V_{\text {Interaction }}^{E}-V_{\text {Free volume }}^{E} \\
& V_{\text {Pressure }}^{E}=\frac{\left(\widetilde{V}_{1}-\widetilde{V}_{2}\right)\left(P_{1}^{*}-P_{2}^{*}\right) \psi_{1} \psi_{2}}{P_{2}^{*} \psi_{1}+P_{1}^{*} \psi_{2}} \\
& V_{\text {Interaction }}^{E}=\frac{\left(\widetilde{V}^{\frac{2}{3}}-1\right) \tilde{V}^{\frac{2}{3}} \psi_{2} \theta_{2} \chi_{12}}{\left((4 / 3) \tilde{V}^{\frac{2}{3}}-1\right) P_{1}^{*}} \\
& V_{\text {Free volume }}^{E}=\frac{\left(\tilde{V}_{1}-\tilde{V}_{2}\right)^{2}\left((14 / 9) \tilde{V}^{-\frac{1}{3}}-1\right) \psi_{1} \psi_{2}}{\left((4 / 3) \tilde{V}^{-\frac{1}{3}}-1\right) \tilde{V}}
\end{aligned}
$$

The Flory's equation of state ${ }^{2}$ had been used for the calculation of the $P^{*}$ and $V^{*}$ parameters in the P-F-P equation. The values for the coefficient of thermal expansion $(\alpha)$ and the coefficient of isothermal compressibility $(\kappa)$ were found experimentally and used for the calculation of the reduced volume and pressure according to the following equation (5-6):
$\tilde{V}_{i}=\frac{\left(1+(4 / 3) \alpha_{i} T\right)^{3}}{\left(1+\alpha_{i} T\right)}$

$P_{i}^{*}=\frac{T \widetilde{V}_{i}^{2} \alpha_{i}}{\kappa_{i}}$

For calculating the fractions of the molecular contact energy, the hard-core volume and the molecular surface, the following equations (7-9) were used:

$\psi_{1}=1-\psi_{2}=\frac{\left(P^{*} \varphi\right)_{1}}{\left[\left(P^{*} \varphi\right)_{1}+\left(P^{*} \varphi\right)_{2}\right]}$

$\varphi_{1}=1-\varphi_{2}=\frac{\left(X V^{*}\right)_{1}}{\left[\left(X V^{*}\right)_{1}+\left(X V^{*}\right)_{2}\right]}$

$\theta_{1}=1-\theta_{2}=\frac{\varphi_{1}}{\left[\varphi_{1}+(S \varphi)_{2} / S_{1}\right]}$

And the ratio of the contact surface was calculated according to the equation (10):

$\frac{s_{1}}{S_{2}}=\left(V_{1}^{*} / V_{2}^{*}\right)^{\frac{1}{3}}$

\section{Eyring-Flory-Huggins (E-F-H) theory}

The dynamic viscosity was calculated according to the E-F-H theory of the following formula:

$\mu V_{m}=N_{A} h e^{\left(\frac{\Delta g^{*}}{R T}\right)}$

Knowing that $\mu, V_{m}, N_{A}, g^{*}, R$ and $T$ are the dynamic viscosity, molar volume of mixture, Avogadro's number, Gibbs activation energy of the flux, gas's constant and temperature, respectively.

The ideal viscosity can be calculated from the equation (12).

$\mu_{i d} V_{m, i d}=N_{A} h e^{\left(\frac{\Delta g^{*} i d}{R T}\right)}$

Two contributions are there for the Gibbs activation energy of viscous flow (ideal and excess contributions) as explained in the equation (13).

$\Delta g^{*}=\Delta g^{*}{ }_{i d}+g_{E}^{*}$

The relation between the real viscosity and the viscosity in the ideal mixing can be differentiated from the equations (11-13).

$\ln \left(\mu V_{m}\right)=\ln \left(\mu V_{m}\right)_{i d}+\frac{g_{E}^{*}}{R T}$

For real and ideal system, the total property equal to the sum of the species properties as in the following equations:

$$
\begin{aligned}
& \ln \left(\mu V_{m}\right)_{i d}=\sum_{i=1}^{2} X_{i} \ln \left(\mu_{i} V_{i}\right) \\
& \ln \left(\mu V_{m}\right)=\sum_{i=1}^{2} X_{i} \ln \left(\mu_{i} V_{i}\right)+\frac{g_{E}^{*}}{R T}
\end{aligned}
$$




\section{Chemical Engineering Research Bulletin 20(2018) 30-35}

Table 1: The values of density $(\rho)$, dynamic viscosity $\mu$, coefficient of thermal expansion $(\alpha)$ and coefficient of isothermal compressibility $(\kappa)$ for the pure DBSA and acetone at $298.15 \mathrm{~K}$.

\begin{tabular}{|c|c|c|c|c|c|c|}
\hline \multirow{2}{*}{ Component } & \multicolumn{2}{|c|}{$10^{-3} \rho,\left(\mathrm{kg} \cdot \mathrm{m}^{-3}\right)$} & \multicolumn{2}{|c|}{$\mu,(\mathrm{mPa} . \mathrm{s})$} & \multirow{2}{*}{$\begin{array}{l}\mathbf{1 0}^{4} \boldsymbol{\alpha} / \mathbf{K}^{-1} \\
\text { Exp. }\end{array}$} & \multirow{2}{*}{$\begin{array}{l}10^{4} \kappa / \mathrm{MPa}^{-} \\
\text {Lit. }\end{array}$} \\
\hline & Exp. & Lit. & Exp. & Lit. & & \\
\hline DBSA & 1.05343 & $1.05354[34]$ & 1056 & $1055.9[34]$ & 1.6327 & 5.874 \\
\hline Acetone & 0.74924 & 0.74879 [35] & 0.33 & $0.329[35]$ & 12.625 & 14.57 \\
\hline
\end{tabular}

Nowing that $\mu_{\mathrm{i}}, V_{i}$ and $X_{i}$ are the viscosity, molar volume and mole fraction of the species (i) in the binary mixture, respectively. Huggins's theory assumes that the total volume of the solution is divided into sets of $\mathrm{N}$ lattice site and the molecules occupy the sites randomly. The Gibbs energy of activation depending on Flory' theory then can be written in the following form (17-19):

$\frac{g_{E}^{*}}{R T}=\left[X_{1} \ln \left(\phi_{1} / X_{1}\right)+X_{2} \ln \left(\phi_{2} / X_{2}\right)\right]+\chi\left(X_{1}+\right.$

$k \times 2 \phi 1 \phi 2$

$\phi_{i}=\frac{\mathrm{X}_{\mathrm{i}} \mathrm{m}_{\mathrm{i}}}{\sum_{\mathrm{i}=1}^{2} \mathrm{X}_{\mathrm{i}} \mathrm{m}_{\mathrm{i}}}$

$k=\frac{m_{2}}{m_{1}}$

\section{Results and Discussion}

\section{Excess molar volume}

For calculating the excess molar volume variation with the mole fraction according to the P-F-P equation, it is important to find the values of thermal expansion coefficient $(\alpha)$ and isothermal compressibility factor $(\kappa)$. The values of thermal expansion values were calculated for the DBSA and Acetone and at different temperature (293.15-303.15 K) depending on the experimental data of density. While, the isothermal compressibility factor values were obtained from the references ${ }^{30,31}$. Table 1 list the values of thermal expansion coefficients, isothermal compressibility factor, density and viscosity values for the pure substances of DBSA and Acetone at the temperature of 298.15 K. The non-ideal behavior was concluded from the non- linearity in the relation between the excess molar volume and viscosity deviation with the mole fraction variation as stated in other studies ${ }^{32,33}$. The PF-P equations was applied for fitting the experimental data of excess molar volume and the $\chi_{12}$ parameter in the three contributions terms of the P-F-P equations (pressure, interaction and free volume) were obtained. The results of the excess molar volume variation with the mole fraction for the P-F-P equation (total effect) and for the three contribution effects at three different temperatures (293.15-303.15 K) were shown in the Figures 1-3. The variation in the excess molar volume shows positive values for all the range of mole fraction and the maximum value was found at the mole fraction of 0.4. The increase in temperature had a positive effect due to the lower of the interaction between the licked molecules and increasing the volume of the solution and provides a space for the large molecule.

\section{Viscosity deviation}

The viscosity deviation was calculated according to the Eyring-Flory-Huggins (E-F-H) theory. Figure 4 shows the variation of viscosity with the mole fraction of DBSA at the temperature range of (293.15-303.15 K). A negative deviation was observed in the Figure 4 for all the values of mole fraction and temperature. Moreover, the deviation become more negative with increasing the temperature due to the decrease the attractive forces between the molecules and the mixture become less viscous.

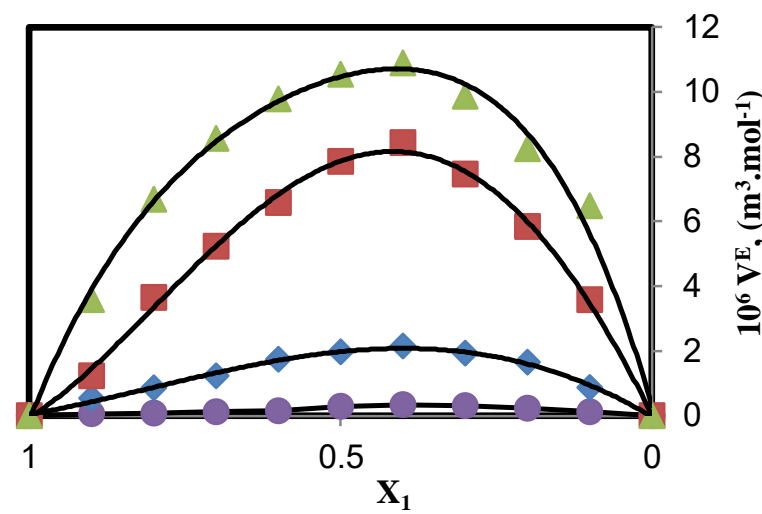

Figure 1: Experimental and correlated excess molar volume $\left(\mathrm{V}^{\mathrm{E}}\right)$ using P-F-P equation as a function of DBSA mole fraction at a temperature $(293.15 \mathrm{~K})$ for the $(\triangle$ P-F-P model, $\square$ interaction term, $\Delta$ free volumeterm, pressure term).

(O)BangladeshUni.ofEngg.\&Tech32 


\section{Chemical Engineering Research Bulletin 20(2018) 30-35}

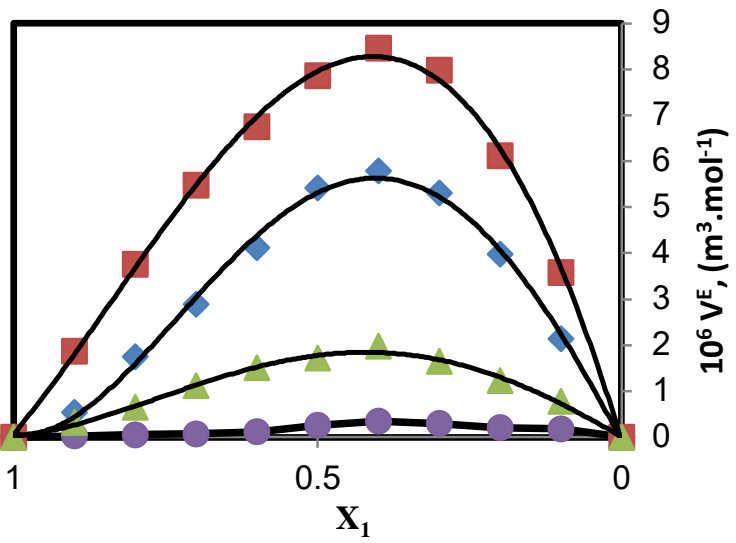

Figure 2: Experimental and correlated excess molar volume $\left(\mathrm{V}^{\mathrm{E}}\right)$ using P-F-P equation as a function of DBSA mole fraction at a temperature $(298.15 \mathrm{~K})$ for the $(\checkmark$ P-F-P model, $\square$ interaction term, $\Delta$ free volume term, $\mathrm{O}$ pressure term) .

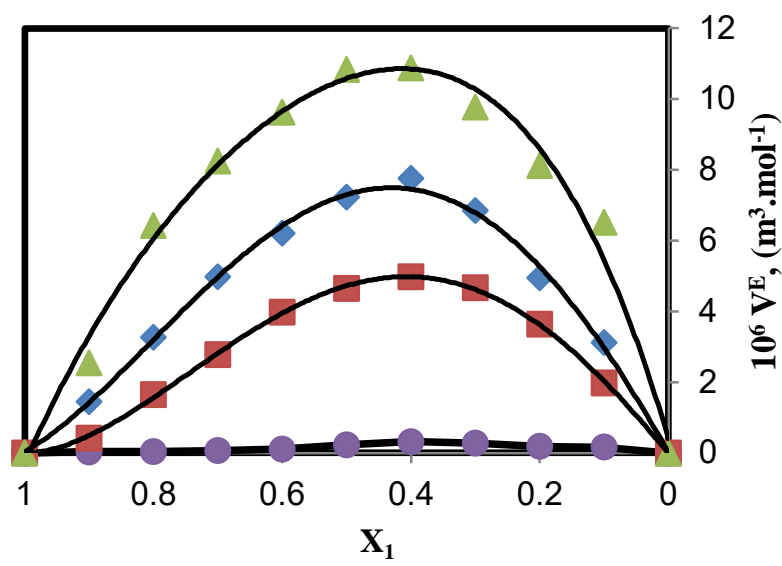

Figure 3: Experimental and correlated excess molar volume $\left(\mathrm{V}^{\mathrm{E}}\right)$ using P-F-P equation as a function of DBSA mole fraction at a temperature $(303.15 \mathrm{~K})$ for the ( P-F-P model, $\square$ interaction term, $\Delta$ free volume term, $\bigcirc$ pressure term) .

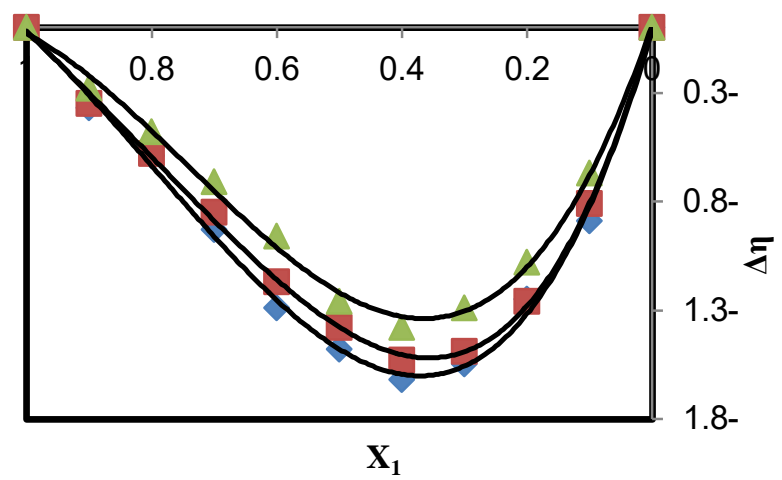

Figure 4: Dynamic viscosity deviation $(\Delta \mu)$ estimated using Eyring-Flory-Huggins (E-F-H) theory as a function of mole fraction of DBSA for the three temperatures as follows ( $293.15, \square 298.15$, $303.15 \mathrm{~K})$.

\section{Conclusion}

The density, viscosity data were measured experimentally for the range of mole fraction at three different temperatures (293.15-303.15 K). PrigogineFlory-Patterson equation correlated the experimental data of excess molar volume properly. The interactional term in the P-F-P equation showed a main effect on the excess molar volume compared to the free volume and the pressure term effect. The lowest effect was the effect of the pressure term. The excess volume showed a positive value for all the mole fraction range. The values become more positive with increase the temperature, which was explained by decreasing the attractive interaction between the molecules. The deviation in viscosity was estimated using Eyring-Flory-Huggins theory and showed a negative deviation. The negativity in deviation was increased with temperature, which make the mixture less viscous due to the reduction in the attractive forces. At high temperature, the large molecule can find a suitable site due to the expansion of the solution volume.

\section{Acknowledgement}

The author acknowledges the help and facility providing by the University of Al-Qadisiyah/College of engineering/Department of chemical engineering.

\section{References}

1. Flory, P. J., Orwoll, R. A., \&Vrij, A. (1964). Statistical thermodynamics of chain molecule liquids. I. An equation of state for normal paraffin hydrocarbons. Journal of the American Chemical Society, 86(17), 3507-3514.

2. Flory, P. J., Orwoll, R. A., \&Vrij, A. (1964). Statistical thermodynamics of chain molecule liquids. II. Liquid mixtures of normal paraffin hydrocarbons. Journal of the American Chemical Society, 86(17), 3515-3520.

3. Barbe, M., \& Patterson, D. (1980). Thermodynamics of mixtures of hexane and heptane isomers with normal and branched hexadecane. Journal of Solution Chemistry, 9(10), 753-769.

4. Van Tra, H., \& Patterson, D. (1982). Volumes of mixing and theP* effect: Part I. Hexane isomers with normal and branched hexadecane. Journal of Solution Chemistry, 11(11), 793-805.

5. Costas, M., \& Patterson, D. (1982). Volumes of mixing and theP* effect: Part II. Mixtures of alkanes 


\section{Chemical Engineering Research Bulletin 20(2018) 30-35}

with liquids of different internal pressures. Journal of Solution Chemistry, 11(11), 807-821.

6. Sastry, N. V., \& Dave, P. N. (1996). Thermodynamics of acrylic esters containing binary liquid mixtures. I. Excess volumes and isentropic compressibilities of alkyl methacrylates+ n-hexane, + n-heptane, + carbon tetrachloride, + chlorobenzene, ando-dichlorobenzene at $303.15 \mathrm{~K}$. International journal of thermophysics, 17(6), 1289-1304.

7. Sastry, N. V., Patel, S. R., \& Prasad, D. H. L. (2000). Measurements and theoretical analysis of excess enthalpies and excess volumes of methyl methacrylate+n-alkanes (n-pentane, n-hexane, nheptane, n-decane and ndodecane). Thermochimicaacta, 359(2), 169-180.

8. Patterson, D., \&Delmas, G. (1970). Corresponding states theories and liquid models. Discussions of the Faraday Society, 49, 98-105.

9. Kermanpour, F., \&Niakan, H. Z. (2012). Experimental excess molar properties of binary mixtures of (3-amino-1-propanol+ isobutanol, 2propanol $)$ at $\mathrm{T}=(293.15$ to 333.15$) \mathrm{K}$ and modelling the excess molar volume by Prigogine-FloryPatterson theory. The Journal of Chemical Thermodynamics, 54, 10-19.

10. Macías-Salinas, R., García-Sánchez, F., \& Hernández-Garduza, O. (2003). Viscosity model for pure liquids based on Eyring theory and cubic EOS. AIChE journal, 49(3), 799-804.

11. Macías-Salinas, R., Durán-Valencia, C., LópezRamírez, S., \&Bouchot, C. (2008). Eyring-theorybased model to estimate crude oil viscosity at reservoir conditions. Energy \& Fuels, 23(1), 464470.

12. Shrikhande, J. J. (2007). p-Dodecylbenzenesulfonic Acid: A Brønsted Acid-Surfactant-Combined Catalyst. RES. J. Chem. Environ., 11, 82.

13. Jing, L., Li, X., Che Li, X., ChunHan, Y. \& Chu, Y. (2008). The Esterification in Cyclohexane/DBSA/Water Microemulsion System. Colloid Surface A: physicochem. Eng., 326, 37.

14. Chai, Y., Dong, D., Ouyang, Y., Liang, Y., Wang,Y., Li, M. \& Liu, Q. (2007). Thia-Michael Addition Reactions in Water Using 3-[Bis(Alkylthio) Methylene] Pentane-2,4-Diones as Odorless and Efficient Thiol Equivalents. Lett. Org. Chem., 4, 281.

15. Shiri, M., \&Zolfigol, M. A. (2009). Surfactant-type catalysts in organic reactions. Tetrahedron, 65(3), $587-598$

16. Manabe, K., Lumura, S., Sun,X. \&Kobayashi,S. (2002). Dehydration Reactions in Water. Brønsted Acid-Surfactant-Combined Catalyst for Ester, Ether,
Thioether, and Dithioacetal Formation in Water $J$. Am. Chem. Soc., 124, 11971.

17. Manabe, K., Mori, Y., \& Kobayashi, S. (2001). Three-component carbon-carbon bond-forming reactions catalyzed by a Brønsted acid-surfactantcombined catalyst in water. Tetrahedron, 57(13), 2537-2544.

18. Haba, Y., Segal, E., Narkis, M., Titelman, G. I., \&Siegmann, A. (1999). Polymerization of aniline in the presence of DBSA in an aqueous dispersion. Synthetic metals, 106(1), 59-66.

19. Machado, D. S., Moraes, S. R., \& Motheo, A. J. (2006). Aspects of the Chemical Synthesis of PAniDBSA and its Properties. Molecular Crystals and Liquid Crystals, 447(1), 215-533.

20. Han, M. G., Cho, S. K., Oh, S. G., \&Im, S. S. (2002). Preparation and characterization of polyaniline nanoparticles synthesized from DBSA micellar solution. Synthetic Metals, 126(1), 53-60.

21. Smail, R. B., Jezorek, R. L., Lejnieks, J., Enayati, M., Grama, S., Monteiro, M. J., \&Percec, V. (2017). Acetone-water biphasic mixtures as solvents for ultrafast SET-LRP of hydrophobic acrylates. Polymer Chemistry, 8(20), 3102-3123.

22. Schindler, W., Sharko, P. T., \& Jonas, J. (1982). Raman study of pressure effects on frequencies and isotropic line shapes in liquid acetone. The Journal of Chemical Physics, 76(7), 3493-3496.

23. Ancian, B., Tiffon, B., \& Dubois, J. E. (1983). Molecular interactions and reorientational motion of neat acetone in the liquid state. $17 \mathrm{O}$ NMR chemical shifts and linewidths at variable temperature. Chemical Physics, 74(2), 171-177.

24. Knözinger, E., \&Wittenbeck, R. (1984). Far-infrared spectra of strongly polar molecules in solid solution: Acetone and nitromethane. Journal of Molecular Spectroscopy, 105(2), 314-323.

25. Jalilian, M. R., \&Zahedi-Tabrizi, M. (2008). Spectra and structure of binary azeotropes $\mathrm{V}$-acetonecyclopentane. SpectrochimicaActa Part A: Molecular and Biomolecular Spectroscopy, 69(1), 278-281.

26. Shikata, T., Sugimoto, N., Sakai, Y., \& Watanabe, J. (2012). Dielectric behaviors of typical benzene monosubstitutes, bromobenzene and benzonitrile. The Journal of Physical Chemistry B, 116(41), 12605-12613.

27. Kollipost, F., Domanskaya, A. V., \&Suhm, M. A. (2014). Microscopic roots of alcohol-ketone demixing: infrared spectroscopy of methanolacetone clusters. The Journal of Physical Chemistry A, 119(11), 2225-2232. 


\section{Chemical Engineering Research Bulletin 20(2018) 30-35}

28. Srivastava, S. K., Ojha, A. K., Koster, J., Shukla, M. K., Leszczynski, J., Asthana, B. P., \& Kiefer, W. (2003). Isotopic dilution, self-association, and Raman non-coincidence in the binary system $(\mathrm{CH} 3)$ $2 \mathrm{C} \square \mathrm{O}+(\mathrm{CD} 3) 2 \mathrm{C} \square$ O reinvestigated by polarized Raman measurement and ab initio calculations. Journal of molecular structure, 661, 11-21.

29. Arivazhagan, G., Elangovan, A., Shanmugam, R., Vijayalakshmi, R., \&Kannan, P. P. (2015). Spectroscopic studies, NBO analysis and dielectric studies on the behaviour of acetone molecules in non-polar solvent environment. Chemical Physics Letters, 627, 101-106.

30. Green, D. W., \& Perry, R. H. (1999). Perry's chemical engineers' handbook.
31. Vargaftik, N. B. (1975). Handbook of physical properties of liquids and gases-pure substances and mixtures.

32. Tahery, R. (2017). Surface tension and density of mixtures of m-xylene+n-alkane at $293.15 \mathrm{~K}$ : Analysis under the extended Langmuir and Shereshefsky models. The Journal of Chemical Thermodynamics, 106, 95-103.

33. Gnanakumari, P., Venkatesu, P., Mohan, K. R., Rao, M. P., \& Prasad, D. H. L. (2007). Excess volumes and excess enthalpies of $\mathrm{N}$-methyl-2-pyrrolidone with branched alcohols. Fluid phase equilibria, 252(1), 137-142. 